\title{
Use of prokinetics and other quality factors in capsule endoscopy - old and new insights (Review)
}

\author{
RALUCA SIMONA COSTACHE ${ }^{1,2}$, ALEXANDRA IOANA LULACHE ${ }^{1}$, MARIANA JINGA ${ }^{1,2}$, \\ CĂTĂLINA VLĂDUȚ ${ }^{3}$, DANIEL OCTAVIAN COSTACHE ${ }^{4}$ and FLORENTINA IONIȚĂ RADU ${ }^{1,5}$ \\ ${ }^{1}$ Department of Gastroenterology, 'Carol Davila' Central Military Emergency University Hospital, 010825 Bucharest; \\ ${ }^{2}$ Internal Medicine and Gastroenterology Discipline, 'Carol Davila' Central Military Emergency University Hospital, \\ 'Carol Davila' University of Medicine and Pharmacy, 050474 Bucharest; ${ }^{3}$ Department of Gastroenterology, \\ 'Prof. Dr. Agrippa Ionescu' Clinical Emergency Hospital, 011356 Bucharest; ${ }^{4}$ Department of Research, \\ 'Carol Davila' Central Military Emergency University Hospital, 010825 Bucharest; \\ ${ }^{5}$ Department of Medical-Surgical and Prophylactic Disciplines, Faculty of Medicine, \\ ‘Titu Maiorescu' University, 004051 Bucharest, Romania
}

Received May 22, 2020; Accepted June 22, 2020

DOI: $10.3892 /$ etm. 2020.8960

\begin{abstract}
Despite the extensive recent development of different techniques for endoscopic evaluation for both diagnostic and therapeutic reasons, the small bowel remains quite difficult to visualize. Capsule endoscopy and device assisted enteroscopy are presently considered the best diagnostic tools for examination of small bowel disorders, assessing diverse pathologies such as obscure gastrointestinal bleeding, iron deficiency anemia, Crohn disease, small bowel tumors and polyposis syndromes. Like any other imagistic method, it has specific indications, and contraindications, and possibly it is more important to consider limitations. In order to obtain a better result, it is necessary to respect the procedural quality indicators. Among them the use of prokinetics - diverse pharmacological substances increasing the success rate of capsule endoscopy have raised debates. Capsule endoscopy small bowel evaluation is a reliable, non-invasive and safe with many advantages and minimum risks, with a proper selection of patients, and can be used as first line investigation.
\end{abstract}

\section{Contents}

1. Introduction

2. History and present position

3. Indications, advantages and limits

4. Quality indicators

Correspondence to: Dr Daniel Octavian Costache, Department of Research, 'Carol Davila' Central Military Emergency University Hospital, 88 Mircea Vulcănescu Street, 010825 Bucharest, Romania E-mail: daniel_costache@yahoo.com

Key words: capsule endoscopy, small bowel, anemia, prokinetics, domperidone
5. Prokinetics

6. Standardization

7. Conclusions

\section{Introduction}

Since the introduction of endoscopic techniques for small and large bowel examination, the small intestine remains difficult to explore despite the advanced technical developments. In recent years, new endoscopic modalities were developed to obtain a better evaluation of the small intestine, including video capsule endoscopy (VCE) and device-assisted enteroscopy. At present, device assisted-enteroscopy is represented by double-balloon enteroscopy, single-balloon enteroscopy, spiral enteroscopy and balloon guided enteroscopy.

Capsule endoscopy was used for the first time in 1997 when the first live image from the pig's gut using a wireless technology was obtained. In 1999 it was used on the first human volunteer and in 2001 it was approved by FDA (Food and Drug Administration) (1). With this technique, an endoluminal examination of the small bowel can be performed using a small device in the shape of a pill which is swallowed and then pushed by gut motility through the gastrointestinal tract. The device obtain images from the mucosa of the gut and wirelessly transmit them to a recording device. The images obtained, more than 50,000, are analyzed by dedicated software and evaluated by the physician. Substantial research has developed the method, and at present, small bowel capsule endoscopy (SBCE), can be used for esophagus and for colon evaluation (2).

\section{History and present position}

Since its introduction in 2000, capsule endoscopy has rapidly become one of the primary diagnostic tools for small bowel disorders, especially in obscure gastrointestinal bleeding (OGIB) $(3,4)$. It is considered that in approximatively $5 \%$ of 
OGIB upper and lower endoscopies are negative and the lesion is located in the small bowel. Therefore, capsule examination should be the first-line examination method for a patient with OGIB before device assisted endoscopy, small bowel radiographic studies, and mesenteric angiography. Some authors consider that capsule endoscopy has a detection rate of the small bowel lesions of $60.5 \%$ (5). The diagnostic yield was considered by Pennazio et al (6) to be higher in patients with active bleeding (92.3\%) or occult bleeding (44.2\%), than in patients with a history of active bleeding (12.9\%).

Another important factor regarding better results for using SBCE in OGIB was time interval after a bleeding episode. Several authors studied the best time for using VCE and all the studies conclude that the early the better, best results being obtained within 14 days after the bleeding episode $(7,8)$.

\section{Indications, advantages and limits}

Capsule endoscopy indeed has its limits, the best results being obtained with device-assisted enteroscopy in patients with positive findings at $\mathrm{SBCE}$ examination, to possibly treat the previously visualized lesions (9).

Another pathology frequently met in clinical practice is iron deficiency anemia. Endoscopic examination of the gut is included in the evaluation protocol after excluding other causes of iron deficiency anemia: medication use, comorbidities including coeliac disease, gynecological history in premenopausal women (10). In these patients, first an upper and lower endoscopy is performed, which can reveal the source of anemia in almost $70 \%$ of cases, and only if no lesion is found SBCE is used for evaluation of the small bowel (11).

In patients with Crohn Disease, conventional ileocolonoscopy is considered to be the best method for a positive diagnosis, considering the possibility of a histopathological result. However, there are some cases with Crohn's disease in the small bowel, located only with normal upper endoscopy and ileocolonoscopy. These are the ideal candidates for using VCE for small bowel examination, with high sensitivity and high negative predictive value $(12,13)$.

Nevertheless, in patients with Crohn's disease, there is a higher risk for capsule retention due to possible small bowel strictures and stenosis. In patients with no obstructive symptoms or no known stenosis, the risk of capsule retention is low, being similar to other indications for $\operatorname{SBCE}(14,15)$.

To increase the specificity and positive predictive value of capsule endoscopy results, an accurate selection of patients is necessary: weight loss, perianal disease, high level of inflammatory markers, raised fecal calprotectin (16).

The risk of capsule retention is higher in patients with diagnosed Crohn's disease (13\%), so to avoid this some extra measures are necessary to be taken $(5,14)$. In these cases, the first line method necessary to assess the extension of disease or to identify strictures is the dedicated cross-sectional imaging of the small bowel. If the SBCE is necessary, the patency capsule is better to be used first to exclude the mechanical obstruction. In the unfortunate event of capsule retention, the conservative treatment is the most appropriate approach (anti-inflammatory drugs, immunomodulators), followed by device-assisted endoscopy if necessary (17).
To speak the same language between capsule readers, some authors proposed activity scores: Capsule Endoscopy Crohn's Disease Activity Index (CECDAI) and Lewis score. The Lewis score divided the small bowel into tertiles and use points for different mucosal findings such as ulcers, stenosis and villous appearance. The CECDAI score use inflammation, the extent of disease and the presence of strictures in a mathematical formula for different parts of the small bowel $(18,19)$.

Despite all the advantages of VCE in small bowel Crohn's disease, if endotherapy is needed, device-assisted enteroscopy is better to be used, which allow therapeutic approach for bleeding, stricture dilatations and retrieval of the capsule in case of retention $(20,21)$.

Small bowel tumors and inherited polyposis syndromes are the other two pathological findings for which SBCE is certainly indicated. There are a group of diseases more likely to be associated with small bowel tumors: non-Hodgkin lymphomas, neuroendocrine tumors, stage IV or stage III melanoma with a positive fecal occult blood test, celiac disease resistant to a gluten-free diet $(22,23)$.

If any lesion is found, either mucosal or submucosal, the use of device-assisted enteroscopy is necessary to confirm in case of submucosal mass or to perform biopsy and tattoo the tumors.

The indication of SBCE in diagnosing celiac disease is limited only to patients that do not accept conventional endoscopy.

\section{Quality indicators}

In general, quality indicators are parameters which apply to specific identified problems, for comparison and potential improvement, and they represent a minimally acceptable standard of care. Their goal is to improve medical care, guarantee competency and discover areas that need more research. In theory, they are divided as structural, process and outcome measures, and concerning the endoscopic procedure, they can be classified in pre-procedural, intra-procedural and post-procedural indicators (24).

Indicators of SBCE are divided into pre-procedure, intra-procedure and post-procedure quality indicators.

Pre-procedural quality indicators that apply before the capsule ingestion are represented by correct indication, rate of adequate bowel preparations, and proper patient selection.

As described before, the main indications of SBCE are: detection of OGIB as well as part of evaluation of unexplained iron deficiency anemia (25); evaluation of small bowel Crohn's disease in patients with normal ileocolonoscopy and suggestive signs of disease, or patients with known Crohn's disease in order to evaluate the extension of lesions; different polyposis syndromes or small bowel tumors; diagnose of celiac disease in patients refusing conventional endoscopy or non-responsive to gluten-free diet treatment (16).

Better evaluations of mucosal findings require adequate bowel preparation. Improper bowel preparation may need alternative investigations or repeated SBCE, increasing the discomfort to the patient and also the costs. The accepted standard preparation is the use of $2 \mathrm{~L}$ polietilen glycol before the capsule ingestion (26). If the use of antifoaming agents has a good impact on quality of small bowel preparation, 
reducing the bubbles within the lumen, the use of prokinetics has limited use only for certain type of patients: history of abdominal surgery, diabetic neuropathy, hypothyroidism, psychotropic drugs, or in patient with gastric transient time more than $60 \mathrm{~min}(27,28)$.

Proper patient selection is necessary for a good and safe evaluation. The main risk in using VCE is capsule retention. Recent studies showed a capsule retention rate of $2.1 \%$ for obscure bleeding, $3.6 \%$ for suspected inflammatory bowel disease and $8.2 \%$ for diagnosed IBD $(29,30)$. The use of the patency capsule can diminish this risk, nevertheless in patients with a high risk of capsule retention precaution is important.

Other concerns regarding patient selection are electromagnetic interference with other devices: pacemakers, implantable cardioverter defibrillators (ICD) and left ventricular assist devices. Different authors published studies with no adverse effects in cardiac pacemaker patients and VCE examinations, but there are less data regarding the ICD (31). The presence of implanted cardiac devices is no longer a contraindication for SBCE.

Pregnancy remains a contraindication for capsule endoscopy because of the absence of safety data.

Another complication of using the VCE is the aspiration at the time of ingestion. For the patients with swallowing difficulties assisted endoscopic administration is recommended (32).

The patient should be informed regarding the procedure: indications, benefits, complications and alternatives, and informed consent must be signed before the procedure.

Procedural quality indicators are: complete cecal visualization, reading and procedure report, lesion detection rate, and capsule retention rate.

Cecal visualization is important to be sure the small bowel examination is complete. A $20 \%$ rate of incomplete examinations is considered to be acceptable $(5,33)$.

\section{Prokinetics}

The main cause for incomplete examination of the small bowel is the prolonged gastric transit time. As mentioned, there are some pathologies with delayed gastric emptying: diabetic neuropathy, hipotiroidism, vagotomy and use of psychotropic agents. In order to obtain a proper small bowel examination, the gastric transit time should not exceed $60 \mathrm{~min}$. There are different types of prokinetics used worldwide for SBCE. The ideal purpose is to shorten the gastric transit time not affecting the small bowel transit time. In use there are metoclopramide, domperidone and erythromycin as prokinetic agents with pros and cons.

Metoclopramide action is correlated with upper gastrointestinal parasympathetic nerve control with pyloric sphincter relaxations with increased amplitude and tonus of antrum contractions (34). A study conducted by Selby (35) on a large number of patients concluded that metoclopramide increase the rate of complete examination with no impact on diagnostic yield. There are scarce information regarding the comparative use of oral (usual dose $10 \mathrm{mg}$ orally $15 \mathrm{~min}$ before capsule) and intravenous administration of metoclopramide.
Another prokinetic agent used in SBCE is domperidone, a dopamine antagonist with no crossover blood-brain barrier with no extrapyramidal side-effects such as metoclopramide. It increase lower esophageal pressure, improve antroduodenal motility and accelerate gastric emptying. A recent prospective cohort study on a large number of patients $(n=649)$ concluded that patients with erythromycin used as prokinetic has a higher rate of complete examinations than the patients with domperidone (36).

Another, possibly an unusual drug, in use for its prokinetic effect is erythromycin. Erythromycin is used mainly as a macrolide antibiotic and also as a motilin agonist interacting with motilin receptors from the bowel and upper gastrointestinal tract accelerating gastric emptying (37). The use of only one doze prior to SBCE diminish some questions regarding the macrolide resistance and the increase of Clostridium Difficile infections. Globally there are trials using erythromycin as prokinetic agent in SBCE but there is no standardized dose (38).

Recently, a group of UK authors lead by Koulaouzidis conducted a meta-analysis regarding the prokinetic use in SBCE. They analyzed 13 studies with a total number of 1,439 patients most of them using metoclopramide, erythromycin and other prokinetic agents. The overall conclusion was prokinetics of any kind have a better completion rate of SBCE (37).

\section{Standardization}

The examination, reading and procedure report should follow the European Society of Gastroenterology and Endoscopy (ESGE) technical review (26). It is considered acceptable for a qualified nurse to pre-read the SBCE examination, followed by the attending physician. The standard reading time is 10 frames per second single view or 20 frames per second in multiple view mode. In this way, a good lesion detection rate is assured. The software can use the automatic mode (the software analyzes all the images and eliminate similar ones) reducing the reading time while maintaining a good lesion detection rate, comparing with manual mode $(36,39)$. The final examination report should be standardized including: i) procedure relating data: type of capsule used, gastric, small bowel transit time and total recording time; ii) the quality of preparation; iii) extent of examination, mentioning the cecal visualization; iv) clinical findings; and v) referral for device-assisted enteroscopy or other investigations. There are some important indications regarding the finding of estimated localizations of the lesions, appreciation of the lesion size, presence of active bleeding, if possible, and use of different types of scoring (ex. CECDAI score for Crohn Disease). Also, regarding the lesion detection rate for overt small bowel bleeding, the time interval from the bleeding episode to the capsule endoscopy examinations is very important, best timing being within 14 days from the bleeding episode $(37,40)$.

The most important complication of capsule endoscopy is capsule retention. The evidence of capsule excretion is an important quality measurement. Studies show that capsule retention remains asymptomatic in most cases, only a rate of $1.9 \%$ of cases was reported to have a patent bowel obstruction (28). The appropriate therapeutic approach, in this case, is device-assisted enteroscopy. Surgery is used as a first-line option in cases of small bowel neoplasia evidenced by capsule 
endoscopy. Some clinical findings are associated with a higher risk of capsule retention: a history of abdominal distension, nausea and vomiting before the examination, history of small bowel surgery, abdominal radiotherapy, and chronic use of high doses of anti-inflammatory drugs (13). Another possible complication is capsule aspiration, with an overall rate of $0.1 \%(38,41)$.

\section{Conclusions}

The major advantage of using capsule endoscopy is represented by the ability to visualize the entire small bowel, it is non-invasive and it is not necessary to use any kind of sedation. On the contrary, one of the major deficiencies is lack of therapeutic options including the possibility of obtaining biopsies. The images can be artefacted by the natural intestinal movement and capsule position in-side the small bowel, intestinal debris, lack of air insufflation. Another important disadvantage is the lack of proper location and dimension of the lesions.

Overall, the capsule endoscopy small bowel examination is a reliable procedure with many advantages and minimum risks for a proper selection of patients (41). Taking into account the good safety profile and the non-invasive nature SBCE can be considered as a first line investigation for patients with small bowel pathology.

\section{Acknowledgements}

Not applicable.

\section{Funding}

No funding was received.

\section{Availability of data and materials}

Not applicable.

\section{Authors' contributions}

RSC conceived and designed the study, coordinated the research and acquired the data. AIL was involved in the conception of the study and acquired the primary data. MJ acquired and interpreted the data. CV was also involved in the conception of the study and drafted the manuscript. DOC edited the final draft and interpreted the data. FIR approved the final version to be published and verified the final interpretation of the data. All authors read and approved the final manuscript.

\section{Ethics approval and consent to participate}

Not applicable.

\section{Patient consent for publication}

Not applicable.

\section{Competing interests}

The authors declare that they have no competing interests.

\section{References}

1. Mazzarolo S and Brady P: Small bowel capsule endoscopy: A systematic review. South Med J 100: 274-280, 2007.

2. Pallag A, Rosca E, ţiT DM, MuŢiu G, Bungău SG and Pop OL: Monitoring the effects of treatment in colon cancer cells using immunohistochemical and histoenzymatic techniques. Rom J Morphol Embryol 56: 1103-1109, 2015.

3. Iddan G, Meron G, Glukhovsky A and Swain P: Wireless capsule endoscopy. Nature 405: 417, 2000.

4. Song HJ and Shim KN: Current status and future perspectives of capsule endoscopy. Intest Res 14: 21-29, 2016.

5. Liao Z, Gao R, Xu C and Li ZS: Indications and detection, completion, and retention rates of small-bowel capsule endoscopy: A systematic review. Gastrointest Endosc 71: 280-286, 2010.

6. Pennazio M, Santucci R, Rondonotti E, Abbiati C, Beccari G, Rossini FP and De Franchis R: Outcome of patients with obscure gastrointestinal bleeding after capsule endoscopy: Report of 100 consecutive cases. Gastroenterology 126: 643-653, 2004

7. Katsinelos P, Chatzimavroudis G, Terzoudis S, Patsis I, Fasoulas K, Katsinelos T, Kokonis G, Zavos C, Vasiliadis T and Kountouras J: Diagnostic yield and clinical impact of capsule endoscopy in obscure gastrointestinal bleeding during routine clinical practice: A single-center experience. Med Princ Pract 20: 60-65, 2011.

8. Bresci G, Parisi G, Bertoni M, Tumino E and Capria A: The role of video capsule endoscopy for evaluating obscure gastrointestinal bleeding: Usefulness of early use. J Gastroenterol 40: 256-259, 2005.

9. Teshima CW, Kuipers EJ, van Zanten SV and Mensink PB: Double balloon enteroscopy and capsule endoscopy for obscure gastrointestinal bleeding: An updated meta-analysis. J Gastroenterol Hepatol 26: 796-801, 2011.

10. Tit DM, Bungau S, Iovan C, Nistor Cseppento DC, Endres L, Sava C, Sabau AM, Furau G and Furau C: Effects of the hormone replacement therapy and of soy isoflavones on bone resorption in postmenopause. J Clin Med 7: 297, 2018.

11. Goddard AF, James MW, McIntyre AS and Scott BB; British Society of Gastroenterology: Guidelines for the management of iron deficiency anaemia. Gut 60: 1309-1316, 2011.

12. Tukey M, Pleskow D, Legnani P, Cheifetz AS and Moss AC: The utility of capsule endoscopy in patients with suspected Crohn's disease. Am J Gastroenterol 104: 2734-2739, 2009.

13. Mow WS, Lo SK, Targan SR, Dubinsky MC, Treyzon L, Abreu-Martin MT, Papadakis KA and Vasiliauskas EA: Initial experience with wireless capsule enteroscopy in the diagnosis and management of inflammatory bowel disease. Clin Gastroenterol Hepatol 2: 31-40, 2004.

14. Höög CM, Bark LA, Arkani J, Gorsetman J, Broström O and Sjöqvist U: Capsule retentions and incomplete capsule endoscopy examinations: An analysis of 2300 examinations. Gastroenterol Res Pract 2012: 518718, 2012.

15. Karagiannis S, Faiss S and Mavrogiannis C: Capsule retention: A feared complication of wireless capsule endoscopy. Scand J Gastroenterol 44: 1158-1165, 2009.

16. Pennazio M, Spada C, Eliakim R, Keuchel M, May A, Mulder CJ, Rondonotti E, Adler SN, Albert J, Baltes P, et al: Small-bowel capsule endoscopy and device-assisted enteroscopy for diagnosis and treatment of small-bowel disorders: European Society of Gastrointestinal Endoscopy (ESGE) Clinical Guideline. Endoscopy 47: 352-376, 2015

17. Goel R, Hardman J, Gulati M and O'Donohue J: Video capsule retention in inflammatory bowel disease: An unusual presentation and discussion of retrieval methods. Case Rep Gastrointest Med 2013: 607142, 2013.

18. Niv Y, Ilani S, Levi Z, Hershkowitz M, Niv E, Fireman Z, O'Donnel S, O'Morain C, Eliakim R, Scapa E, et al: Validation of the Capsule Endoscopy Crohn's Disease Activity Index (CECDAI or Niv score): A multicenter prospective study. Endoscopy 44: 21-26, 2012

19. Gralnek IM, Defranchis R, Seidman E, Leighton JA, Legnani P and Lewis BS: Development of a capsule endoscopy scoring index for small bowel mucosal inflammatory change. Aliment Pharmacol Ther 27: 146-154, 2008.

20. Manes G, Imbesi V, Ardizzone S, Cassinotti A, Pallotta S and Porro GB: Use of double-balloon enteroscopy in the management of patients with Crohn's disease: Feasibility and diagnostic yield in a high-volume centre for inflammatory bowel disease. Surg Endosc 23: 2790-2795, 2009. 
21. Tica OA, Tica O, Antal L, Hatos A, Popescu MI, Pantea Stoian A Bratu OG, Găman MA, Pițuru SM and Diaconu CC: Modern ora anticoagulant treatment in patients with atrial fibrillation and heart failure: Insights from the clinical practice. Farmacia 66 : 972-976, 2018

22. Frilling A, Smith G, Clift AK and Martin J: Capsule endoscopy to detect primary tumour site in metastatic neuroendocrine tumours. Dig Liver Dis 46: 1038-1042, 2014.

23. Barret M, Malamut G, Rahmi G, Samaha E, Edery J, Verkarre V, Macintyre E, Lenain E, Chatellier G, Cerf-Bensussan N, et al: Diagnostic yield of capsule endoscopy in refractory celiac disease. Am J Gastroenterol 107: 1546-1553, 2012.

24. Rizk MK, Sawhney MS, Cohen J,Pike IM, AdlerDG, Dominitz JA, Lieb JG II, Lieberman DA, Park WG, Shaheen NJ, et al: Quality indicators common to all GI endoscopic procedures. Am J Gastroenterol 110: 48-59, 2015.

25. Manea M, Marcu D, Pantea Stoian A, Gaman MA, Gaman AM, Socea B, Neagu TP, Stanescu AMA, Bratu OG and Diaconu CC: Heart failure with preserved ejection fraction and atrial fibrillation: A review. Rev Chim 69: 4180-4184, 2018.

26. Park SC, Keum B, Seo YS, Kim YS, Jeen YT, Chun HJ, Um SH, Kim CD and Ryu HS: Effect of bowel preparation with polyethylene glycol on quality of capsule endoscopy. Dig Dis Sci 56: $1769-1775,2011$

27. RondonottiE,Spada C,Adler S,May A,DespottEJ,Koulaouzidis A, Panter S, Domagk D, Fernandez-Urien I, Rahmi G, et al: Small-bowel capsule endoscopy and device-assisted enteroscopy for diagnosis and treatment of small-bowel disorders: European Society of Gastrointestinal Endoscopy (ESGE) Technical Review. Endoscopy 50: 423-446, 2018.

28. Kotwal VS, Attar BM, Gupta S and Agarwal R: Should bowel preparation, antifoaming agents, or prokinetics be used before video capsule endoscopy? A systematic review and meta-analysis. Eur J Gastroenterol Hepatol 26: 137-145, 2014.

29. Rezapour M, Amadi C and Gerson LB: Retention associated with video capsule endoscopy: Systematic review and meta-analysis. Gastrointest Endosc 85: 1157-1168.e2, 2017.

30. Abdel-Daim MM, El-Tawil OS, Bungau SG and Atanasov AG: Applications of antioxidants in metabolic disorders and degenerative diseases: Mechanistic approach. Oxid Med Cell Longev 2019: 4179676, 2019.

31. Bandorski D, Jakobs R, Brück M, Hoeltgen R, Wieczorek M and Keuchel M: Capsule endoscopy in patients with cardiac pacemakers and implantable cardioverter defibrillators: (re)evaluation of the current state in Germany, Austria, and Switzerland 2010 Gastroenterol Res Pract 2012: 717408, 2012.
32. Bandorski D, Kurniawan N, Baltes P, Hoeltgen R, Hecker M, Stunder D and Keuchel M: Contraindications for video capsule endoscopy. World J Gastroenterol 22: 9898-9908, 2016.

33. Lim YJ, Lee OY, Jeen YT, Lim CY, Cheung DY, Cheon JH, Ye BD, Song HJ, Kim JS, Do JH, et al; Korean Gut Image Study Group: Indications for detection, completion, and retention rates of small bowel capsule endoscopy based on the 10-year data from the Korean Capsule Endoscopy Registry. Clin Endosc 48: 399-404, 2015.

34. Schwarzberg MN: Pro-kinetic medications as aids in imaging the small bowel by video-capsule. Med Hypotheses 64: 602-607, 2005.

35. Selby W: Complete small-bowel transit in patients undergoing capsule endoscopy: Determining factors and improvement with metoclopramide. Gastrointest Endosc 61: 80-85, 2005.

36. Westerhof J, Weersma RK, Hoedemaker RA and Koornstra JJ: Completion rate of small bowel capsule endoscopy is higher after erythromycin compared to domperidone. BMC Gastroenterol 14: 162,2014

37. Koulauzidis A, Giannakou A and Yung DE: PTU-023. The use of prokinetics in small bowel capsule endoscopy: A systematic review and meta-analysis. Gut 62 (Suppl 1): A52, 2013.

38. Hosoe N, Rey JF, Imaeda H, Bessho R, Ichikawa R, Ida Y, Naganuma M, Kanai T, Hibi T and Ogata H: Evaluations of capsule endoscopy software in reducing the reading time and the rate of false negatives by inexperienced endoscopists. Clin Res Hepatol Gastroenterol 36: 66-71, 2012.

39. Singh A, Marshall C, Chaudhuri B, Okoli C, Foley A, Person SD, Bhattacharya $\mathrm{K}$ and Cave DR: Timing of video capsule endoscopy relative to overt obscure GI bleeding: Implications from a retrospective study. Gastrointest Endosc 77: 761-766, 2013.

40. Yung DE, Plevris JN and Koulaouzidis A: Short article: Aspiration of capsule endoscopes: a comprehensive review of the existing literature. Eur J Gastroenterol Hepatol 29: 428-434, 2017.

41. Costache RS: Capsule endoscopy. Rom J Mil Med CXVIII: 33, 2015. 